\title{
Análise da capacidade de infiltração em pavimento permeável de bloco de concreto unidirecionalmente articulado
}

\author{
Bruno Watanabe Ono ${ }^{1}$, José Tadeu Balbo ${ }^{2}$, Andréia Posser Cargnin ${ }^{3 凶}$ \\ ${ }^{1}$ Laboratório de Mecânica de Pavimentos, LMP, brunoono@usp.br \\ 2Departamento de Engenharia de Transportes, PTR, jotbalbo@usp.br \\ ${ }^{3}$ Escola Politécnica da Universidade de São Paulo, EPUSP, andreiacargnin@usp.br
}

\section{Recebido:}

01 de fevereiro de 2017

Aceito para publicação:

26 de setembro de 2017

Publicado:

29 de outubro de 2017

Editor de área:

Francisco Thiago Aragão

\section{Palavras-chaves:}

Pavimentos permeáveis,

Blocos de concreto articulados,

Permeabilidade.

\section{Keywords:}

Permeable pavements,

Articulated concrete blocks,

Permeability.

DOI:10.14295/transportes.v25i3.1314

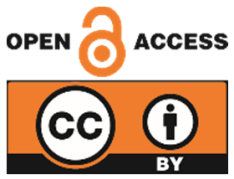

\begin{abstract}
RESUMO
A adoção de pavimentos permeáveis tem se tornado cada vez mais necessária como medida compensatória para amortecer as vazões de pico e atenuar os efeitos causados pelas chuvas em áreas densamente urbanizadas. Usualmente constituídos de revestimentos feitos com blocos de concreto intertravados, concreto poroso ou camada porosa de atrito, os pavimentos permeáveis tradicionais nem sempre apresentam permeabilidade satisfatória. Nesse contexto, esse trabalho avaliou a capacidade de infiltração in situ de blocos de concreto unidirecionalmente articulados como material de revestimento alternativo, diferenciados por sua estrutura e formato geométrico. Para isso, construiu-se uma pista experimental $(20 \times 5 \mathrm{~m})$ no Campus da USP, o que permitiu a realização de ensaios para determinação da taxa de infiltração em campo. Dessa forma, comparou-se os valores encontrados com outros materiais descritos na literatura. Os resultados dos testes mostraram que o material possui permeabilidade elevada da ordem de $10^{-3} \mathrm{~m} / \mathrm{s}$, sendo consideravelmente maior que a de pavimentos feitos tanto com blocos intertravados como também com asfalto poroso.
\end{abstract}

\begin{abstract}
The adoption of permeable pavements has become increasingly necessary as a compensatory measure in order to attenuate peak flows and mitigate the effects caused by rainwater in densely urbanized areas. Usually composed of interlocked concrete blocks, pervious concrete or porous asphalt, the traditional permeable pavements do not always comply with the required levels of permeability. In this context, this paper analyzed the in situ infiltration capacity of articulated concrete blocks as alternative material for surface layer, differentiated by their structure and geometrical design. Therefore, a $20-\mathrm{m}$ long and 5-m-wide pavement test section was constructed at the University of São Paulo Campus, which allowed determining the permeability coefficient in a field evaluation. Hence, the values obtained were compared to those from the pertinent literature using conventional materials. The test results showed that the articulated concrete block presents a high permeability of around $10^{-3} \mathrm{~m} / \mathrm{s}$, being considerably greater than those found in pavements built with both interlocked concrete blocks and with porous asphalt.
\end{abstract}

\section{INTRODUÇÃO}

Nas últimas décadas, o processo de urbanização nas grandes cidades intensificou-se progressivamente. Nesse ritmo, a falta de planejamento aliada à ocupação desordenada do solo resultou em altas taxas de impermeabilização comprometendo os sistemas de drenagem durante os picos de cheia. Dentre os principais impactos desse fenômeno para o ciclo hidrológico, Tucci e Tozzi (1998) apontam o aumento do escoamento superficial e da vazão máxima, e, por conseguinte, aumento do número de enchentes, além da contaminação da qualidade das águas pluviais (Araújo, Tucci e Goldenfum, 2000). 
Ao não ser corretamente drenada, a água pluvial traz sérias consequências ambientais e sociais, aumentando o risco de desabamentos, inundações, erosões e assoreamento das bacias de amortecimento de cheias, o que agrava ainda mais o problema tornando-o insustentável em longo prazo.

Nesse sentido, visando solucionar ou minimizar tais efeitos, além dos dispositivos convencionais como medidas estruturais na macrodrenagem existem também elementos que podem auxiliar no controle direto na fonte, destacando-se entre eles, os pavimentos permeáveis como medida compensatória na drenagem urbana (Tucci e Bertoni, 2003). Capazes de promover a infiltração das águas da chuva no pavimento, eles atuam como um retardador dos tempos de pico das cheias agindo diretamente sobre $o$ hidrograma da bacia local (ASCE, 1992).

Existem vários tipos de revestimentos que podem ser considerados permeáveis, dentre eles, o revestimento poroso, seja concreto asfáltico poroso (CPA) ou concreto de cimento Portland poroso e os blocos de concreto intertravados, comumente utilizados no Brasil (Pinto, 2011). De acordo com a NBR 16416 (ABNT, 2015), os pavimentos de blocos intertravados permeáveis podem ser feitos basicamente com três tipos de revestimento: peças de concreto com juntas alargadas, peças de concreto permeável e peças de concreto com aberturas de drenagem ou áreas vazadas.

No revestimento de peças de concreto com juntas alargadas, a percolação da água ocorre pelas juntas entre as peças de concreto (ABNT, 2015). Tratam-se de blocos de utilização comum em pavimentação que contam com o auxílio de espaçadores para a criação da junta mais larga no momento da execução (Virgiliis, 2009). Já o bloco de concreto poroso possui uma estrutura aberta que o torna permeável sobre a totalidade do seu volume graças a uma composição específica do concreto, conforme explica Sales (2008). Por fim, o revestimento de blocos de concreto com áreas vazadas é uma estrutura composta, na maioria das vezes, de aberturas em forma de meia-lua que permitem a infiltração da água existente na superfície (Virgiliis, 2009).

Apesar desses três tipos de revestimentos serem usados com certa frequência no Brasil e no mundo, existem outros formatos cuja tecnologia e desenho geométrico envolvidos podem apresentar desempenho tão bom quanto ou até mesmo superior em termos de permeabilidade. Nesse contexto, convém ressaltar os blocos de concreto articulados, recentemente adotados nos Estados Unidos e na Coréia do Sul, os quais aparentam ter uma capacidade de infiltração bastante promissora (SMG, 2014; Weiss et al., 2015). Devido à presença de articulações unidirecionais, as peças foram projetadas para trabalhar em conjunto de forma exclusivamente encaixada, dispensando qualquer tipo de material de rejunte. 0 correto espaçamento entre os blocos no sentido não articulado somado com a ausência de finos (areia de rejunte) propiciam um revestimento com elevada permeabilidade.

A fim de se avaliar a taxa de infiltração in situ de um pavimento permeável com um tipo alternativo de revestimento permeável, construiu-se em Maio de 2016 a primeira pista experimental de blocos de concreto unidirecionalmente articulados que se tem registro no Brasil, destinada à área de estacionamento para veículos leves no campus da USP de São Paulo (capital). Além de determinar a capacidade de infiltração em campo, essa pesquisa também buscou comparar os resultados obtidos com estudos já realizados em condições tropicais brasileiras usando outros tipos de revestimentos permeáveis como o bloco de concreto intertravado e a camada porosa de atrito. Ademais, analisou-se a influência de dois tipos de materiais de base (agregado reciclado, também conhecido como resíduo de construção e demolição ou RCD e agregado natural) na permeabilidade do trecho experimental construído.

\section{MATERIAIS, MÉTODOS E CONSTRUÇÃO DO PAVIMENTO}

A pesquisa envolveu tanto a parte de avaliação individual das peças de concreto em laboratório baseando-se na NBR 9781 - Especificação e métodos de ensaio para peças de concreto para pavimentação (ABNT, 2013), como também a análise de desempenho de permeabilidade do pavimento em campo. Para isso, uma pista experimental foi construída dentro do campus da USP de São Paulo, tornando possível a realização do ensaio de taxa de infiltração preconizado pela C1701 (ASTM, 2009) recentemente incoporada pela NBR 16416 (ABNT, 2015) a qual denomina o mesmo ensaio de coeficiente de permeabilidade. 


\subsection{Caracterização dos blocos de concreto}

Com $20 \mathrm{~cm}$ de comprimento por $20 \mathrm{~cm}$ de largura e $8 \mathrm{~cm}$ de altura, o bloco de concreto possui na sua superfície inferior duas cavidades na direção transversal à peça que permitem a passagem da água para drenos auxiliares, como pode ser visto na Figura 1a.

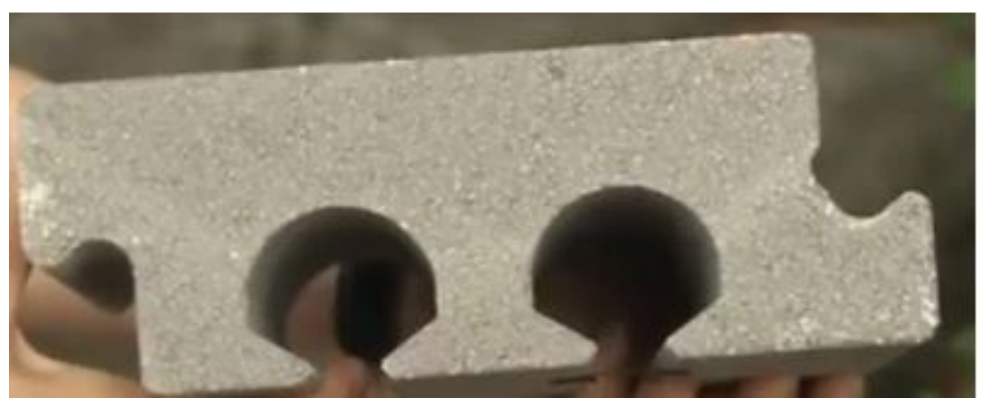

(a)

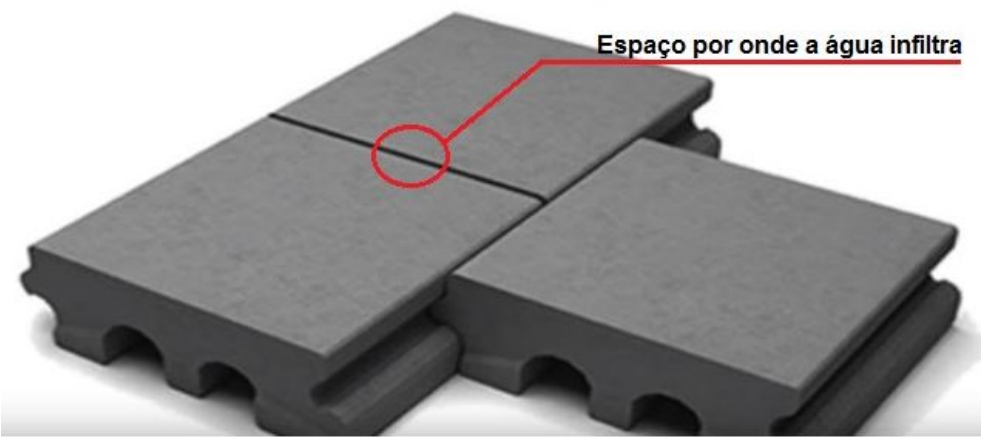

(b)

Figura 1. Bloco de concreto articulado unidirecionalmente: (a) vista longitudinal e (b) vista isométrica

Além disso, a peça caracteriza-se pela presença de articulações na direção longitudinal que possibilita o fácil encaixe e travamento dos blocos, fazendo com que trabalhem em conjunto como uma estrutura única. Assim, não é necessário material de rejunte para garantir o intertravamento, conferindo agilidade ao processo executivo.

Em relação à permeabilidade, a percolação da água pluvial ocorre através dos espaços formados entre os blocos de aproximadamente $1 \mathrm{~mm}$ (Figura 1b). Ressalta-se nesse aspecto a presença de uma saliência de $0,5 \mathrm{~mm}$ em cada face longitudinal que assegura o correto espaçamento entre eles. Nesse sentido, destaca-se que toda a permeabilidade do bloco se dá pela junta, não havendo nenhuma percolação da água pelo concreto em si, uma vez que para a fabricação das peças foi utilizado um concreto típico de blocos de concreto tradicionais, levando em sua composição cimento, pedrisco, areia fina e pó de pedra.

Buscando atender às especificações e requisitos da NBR 9781 - Peças de concreto para pavimentação (ABNT, 2013), foram realizados a avaliação dimensional e o ensaio de absorção de água como constam na citada Norma. A Tabela 1 apresenta o resumo das especificações.

Tabela 1: Resumo das especificações da peça e limites estabelecidos pela NBR 9781 (ABNT, 2013)

\begin{tabular}{lll}
\hline Avaliação & Resultados da peça & Limites estabelecidos pela NBR 9781 (ABNT, 2013) \\
\hline Análise & Comprimento: $199 \mathrm{~mm}$ & Comprimento: tolerância de $\pm 3 \mathrm{~mm}$ \\
\hline \multirow{2}{*}{ Dimensional } & Largura: $201 \mathrm{~mm}$ & Largura: tolerância de $\pm 3 \mathrm{~mm}$ \\
& Espessura: $83 \mathrm{~mm}$ & Espessura: tolerância de $\pm 3 \mathrm{~mm}$ \\
\hline Absorção de água & $5,52 \%$ & $<7 \%$ \\
\hline
\end{tabular}

Cabe ponderar que a NBR 9781 (ABNT, 2013) estabelece requisitos e especificações para peças de concreto para pavimentação intertravada, não abrangendo peças articuladas, como as da pesquisa em questão. Sendo assim, alguns procedimentos de ensaio descritos como o de resistência característica à 
compressão tornam-se inadequados devido à limitação da Norma somente às peças intertravadas e em formatos convencionais. Devido à área da superfície do bloco estudado ser diferente da área inferior que transmite o carregamento, questiona-se qual deveria ser a real área para efeito de cálculo da resistência à compressão da peça. Contudo, na ausência de normas mais apropriadas, o estudo orientou-se pela NBR 9781 (ABNT, 2013) para estabelecer outros parâmetros necessários às peças de concreto de forma geral, como os indicados na Tabela 1, excetuando a resistência característica à compressão, por motivos já citados.

\subsection{Construção da pista experimental}

O pavimento teste foi construído no mês de Maio de 2016 no estacionamento da Escola Politécnica, em frente ao Edifício Paula Souza da Engenharia Civil. 0 local foi escolhido por ser destinado a veículos leves (rotatividade diária inferior a 50 veículos), livre de interferências e por ser de fácil acesso. 0 trecho experimental possui $5 \mathrm{~m}$ de largura e $20 \mathrm{~m}$ de extensão, com capacidade de 7 vagas para veículos de passeio.

A seção possui camada de revestimento com blocos de concreto unidirecionalmente articulados de 8 $\mathrm{cm}$ de espessura, sobre uma camada de areia de assentamento de $3 \mathrm{~cm}$ de espessura. Logo abaixo, utilizou-se uma manta geotêxtil para evitar a perda de material fino. Já a base apresenta $20 \mathrm{~cm}$, sobre um subleito impermeabilizado com geomembrana de polietileno, garantindo que toda água infiltrada no pavimento seja direcionada aos drenos. A Figura 2 esquematiza a seção longitudinal e transversal do pavimento permeável executado.

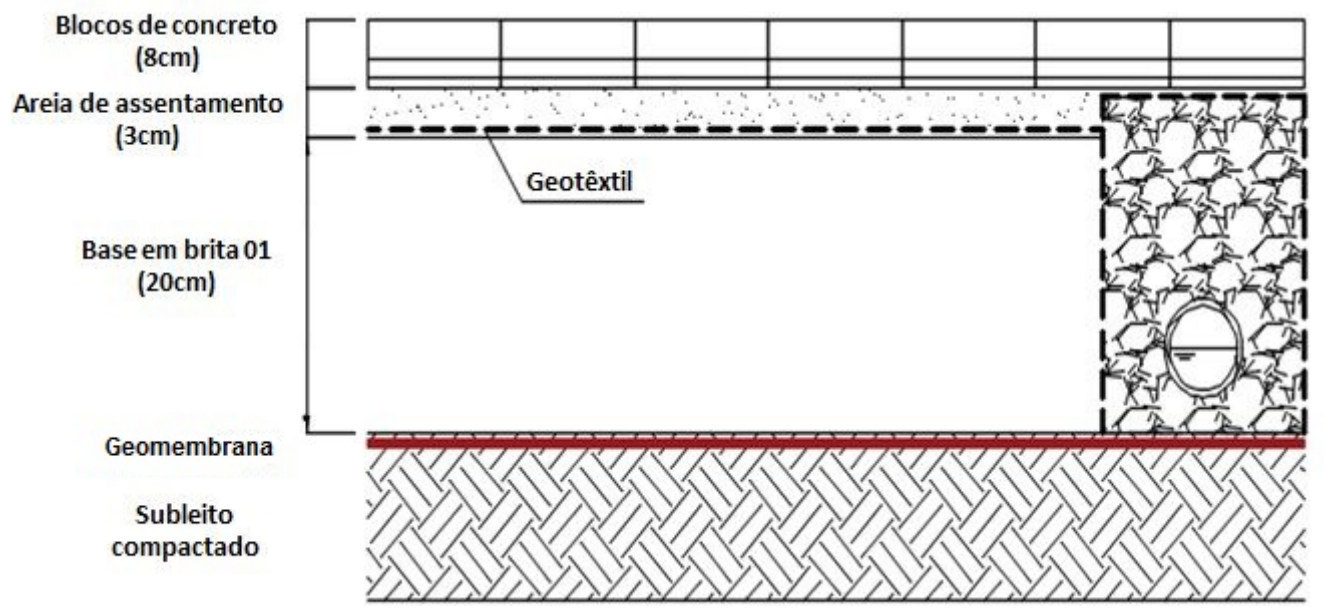

(a)

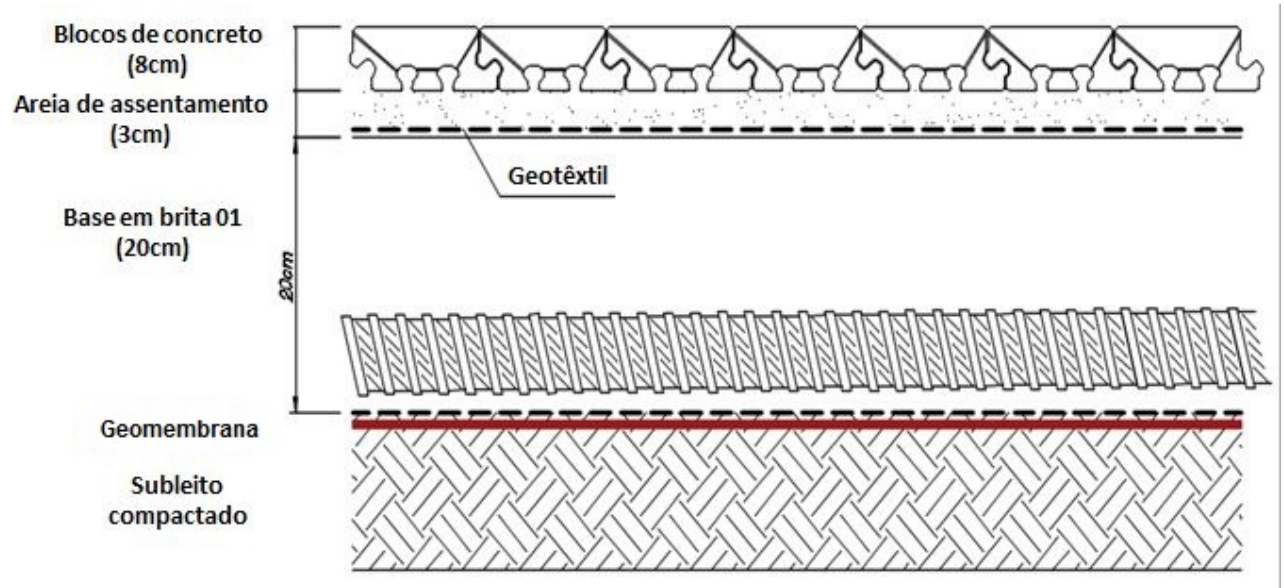

(b)

Figura 2. Seção do pavimento executado: (a) seção transversal e (b) seção longitudinal 
Com o intuito de estudar a influência de dois tipos de materiais granulares para bases em pavimentos permeáveis, empregou-se agregado reciclado na primeira metade do pavimento e agregado natural (graduação comercial do tipo brita 1 - agregados variando entre 9,5 e $19 \mathrm{~mm}$ ) na outra, cujas granulometrias podem ser vistas na Figura 3. As áreas foram divididas igualmente e separadas por uma parede de alvenaria visando impedir a passagem de água entre os tipos de bases.

0 processo construtivo se estendeu por dois dias ininterruptos. Primeiramente, iniciaram-se os trabalhos de escavação e abertura de vala drenante (Figura 4a), garantindo a declividade necessária para o funcionamento do sistema. Em seguida, procedeu-se com a abertura na caixa de concreto da boca de lobo a jusante, de modo a interligar os drenos à galeria pluvial existente no local possibilitando a passagem e medição do fluxo de água. Posteriormente, foi realizada a compactação do subleito com placa vibratória, elevação da parede de alvenaria para separação das áreas das bases e por fim foi colocada a geomembrana de polietileno sobre toda a extensão do subleito nessa primeira etapa construtiva.

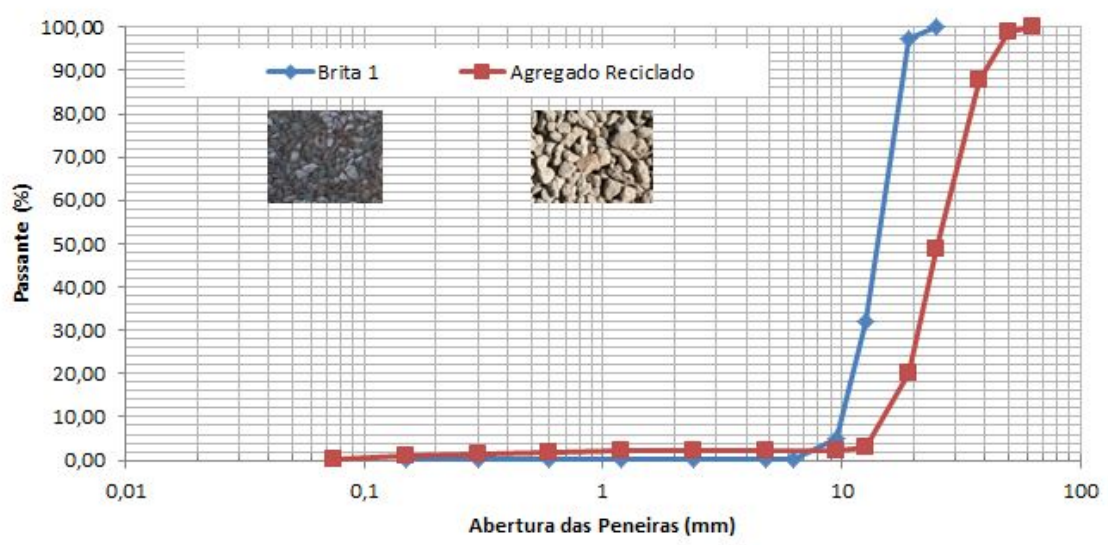

Figura 3. Curva granulométrica dos materiais empregados como base

Na segunda etapa, realizou-se a montagem da trincheira drenante do pavimento na vala aberta anteriormente (Figura 4b). Dentro dela, colocou-se uma manta geotêxtil, preenchendo-a com brita a fim de acomodar as tubulações tanto corrugada como de PVC. Salienta-se que a tubulação da base de agregado natural (área com cota superior) era corrugada até o encontro da parede de alvenaria com o intuito de permitir a captação da água. No entanto, após a passagem da parede, usou-se uma luva para conectar o tubo corrugado com um de PVC, para evitar a mistura das águas provenientes de bases diferentes. Sobre as tubulações, foi colocada mais brita e fechou-se a manta geotêxtil, concluindo o processo de montagem do dispositivo.

Com a trincheira drenante finalizada, foi possível executar a base do pavimento. Após a colocação tanto do agregado natural, como do agregado reciclado, utilizou-se uma pequena quantidade de pedrisco como material de fechamento e camada de transição entre a base e a camada de assentamento. Em seguida, compactou-se o local por meio de placa vibratória e deu-se início à etapa final.

Na última fase, a base foi separada com geotêxtil e sobre ele colocou-se a areia de assentamento. Com o nivelamento da altura de areia realizado, os blocos de concreto foram sendo encaixados e colocados um a um de forma a garantir a correta amarração e articulação da estrutura. Destaca-se que nessa etapa construtiva foram inseridos em pontos estratégicos do pavimento alguns blocos sem articulação, denominados de peças-chaves. Tais blocos funcionam de maneira intertravada e não mais articulada, possibilitando sua retirada e a fácil substituição dos blocos ao redor em caso de quebra, trinca ou demais defeitos. Finalmente, a camada de revestimento foi compactada com placa vibratória e em seguida foi feito o fechamento da contenção lateral utilizando-se miniguias (Figura 4c). 

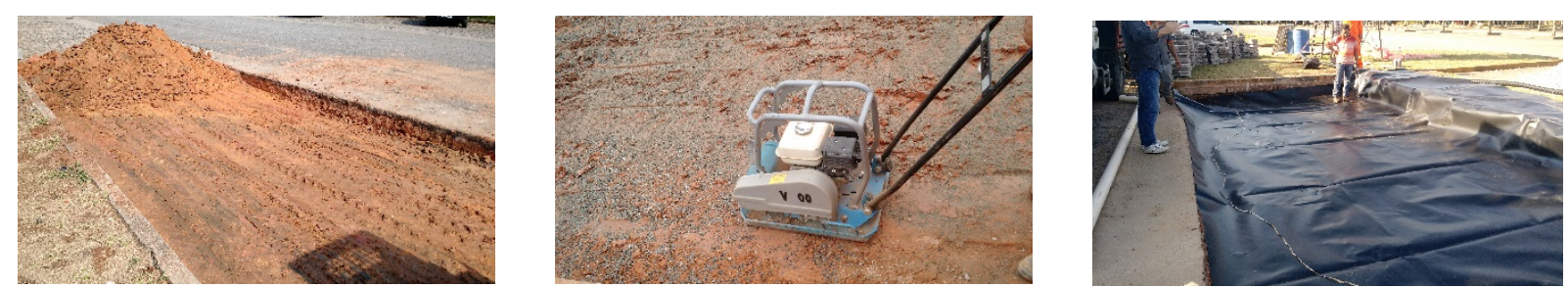

(a) Primeira etapa: escavação, compactação do subleito e colocação da geomembrana
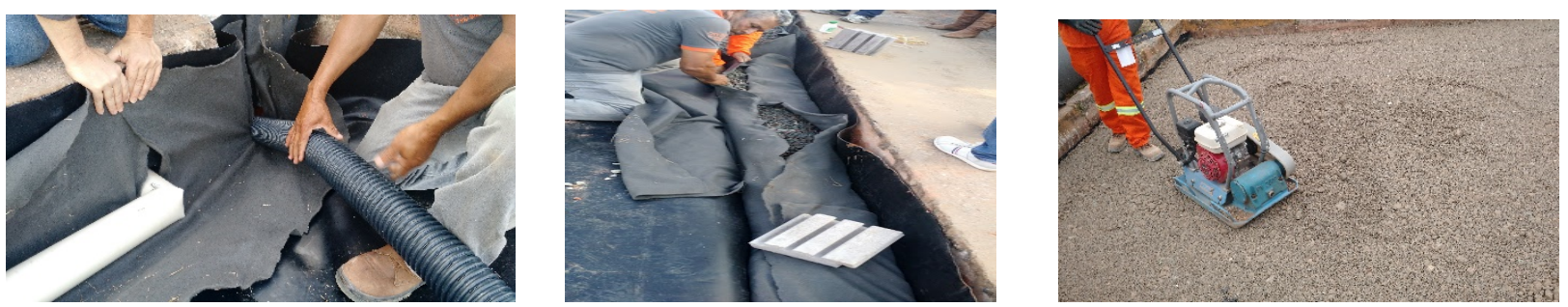

(b) Segunda etapa: montagem da trincheira drenante e execução da base
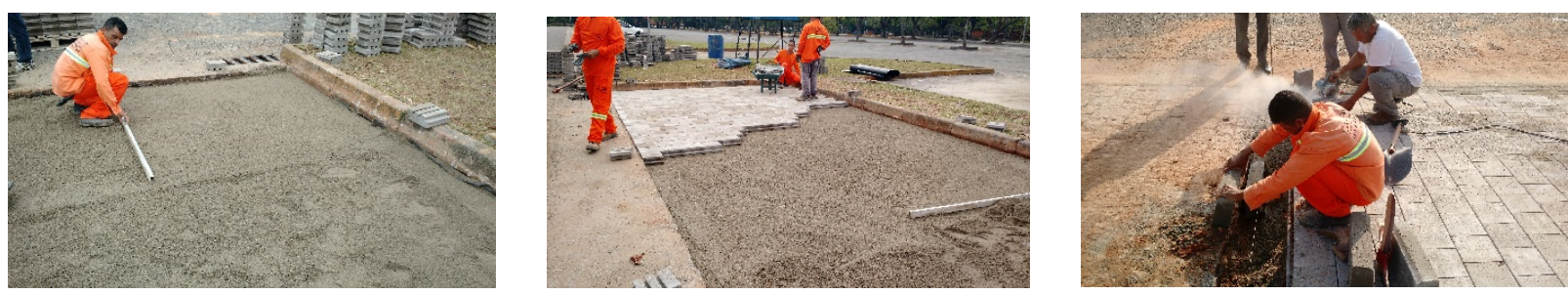

(c) Terceira etapa: nivelamento da areia de assentamento, encaixe dos blocos e fechamento da contenção lateral Figura 4. Processo construtivo do pavimento: (a) primeira etapa; (b) segunda etapa e (c) terceira etapa

\subsection{Método de ensaio de permeabilidade in situ}

Para a determinação da taxa de infiltração in situ do pavimento permeável construído, utilizou-se o método de ensaio descrito pela ASTM C1701 - Standard Test Method for Infiltration Rate of in Place Pervious Concrete, recentemente incorporado à NBR 16416 - Pavimentos Permeáveis de Concreto (ABNT, 2015).

Na realização do teste foram utilizados os seguintes materiais: cilindro aberto em ambas as extremidades com $30 \mathrm{~cm}$ de diâmetro interno ou anel de infiltração, recipiente reservatório e medidor de água com volume mínimo de 20 L, cronômetro, massa de calafetar e água. Antes de iniciar o ensaio, determinou-se a quantidade e localização dos pontos a serem analisados atentando-se para as especificações de lote de ensaio exigidas: mínimo de três pontos para áreas de até $2500 \mathrm{~m}^{2}$ e um ponto a mais para cada $1000 \mathrm{~m}^{2}$ adicionais, com pelo menos $1 \mathrm{~m}$ livre de distância entre eles. Para fins acadêmicos, optou-se por 8 pontos de avaliação bem distribuídos e igualmente espaçados, abrangendo tanto a área do pavimento com base de agregado reciclado (pontos 1, 2, 5 e 6) como a área com base de brita 1 (pontos 3, 4, 7 e 8) - vide Figura 5.

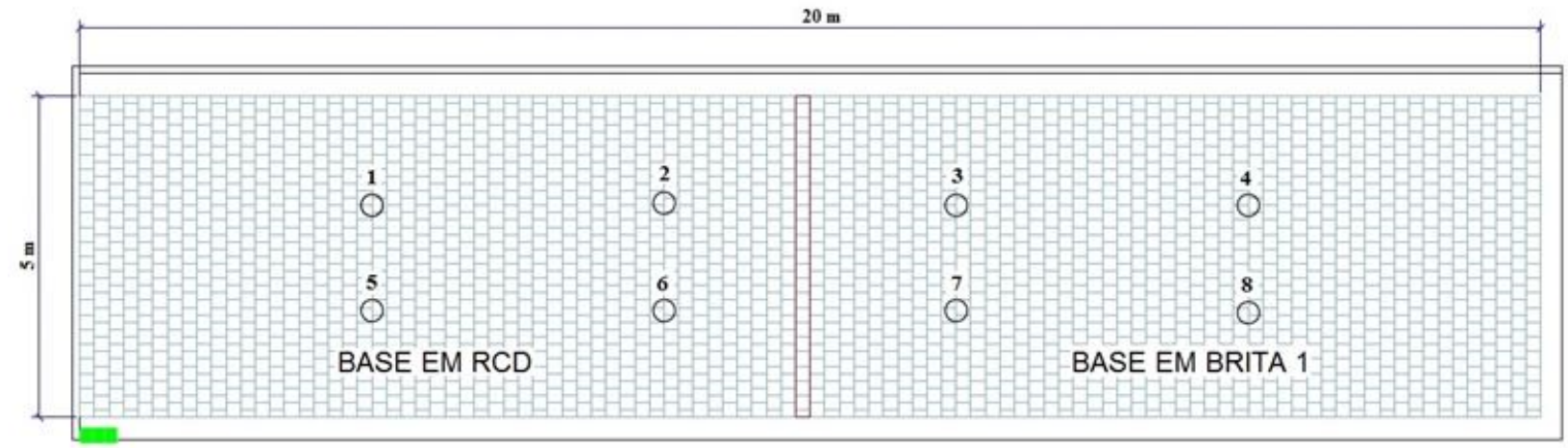

Figura 5. Distribuição dos pontos para realização do ensaio de permeabilidade in situ (vista superior) 
Seguindo os procedimentos recomendados, primeiramente foi efetuada a limpeza e varrição do revestimento para a retirada de sedimentos depositados e não aderidos à superfície (Figura 6a). Sequencialmente, posicionou-se o anel de infiltração no ponto a ser ensaiado e foi feita a vedação da área de contato com o pavimento aplicando-se massa de calafetar, para não permitir vazamentos (Figura 6b).

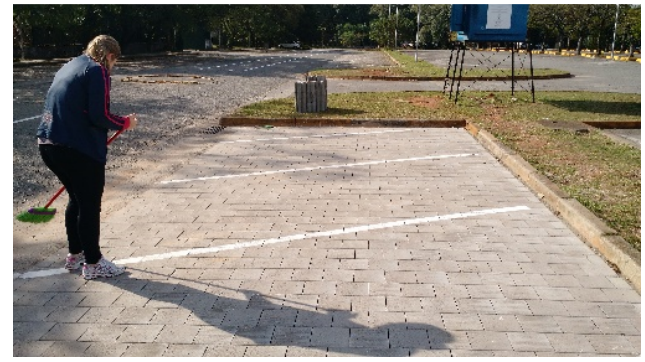

(a)

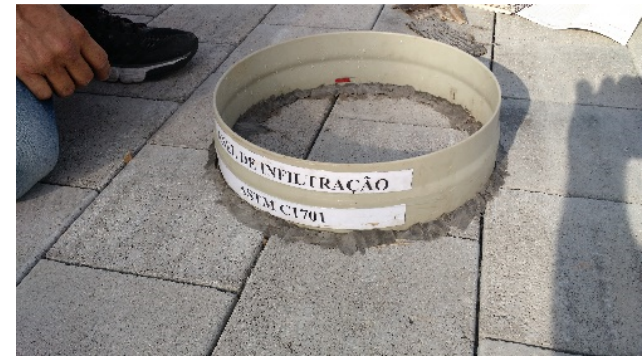

(b)

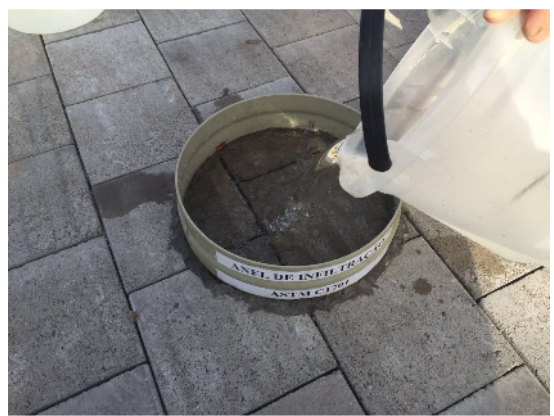

(c)

Figura 6. Etapas do procedimento de ensaio: (a) varrição do revestimento; (b) vedação do anel de infiltração com massa de calafetar; (c) pré-molhagem e despejo de água

Com o dispositivo devidamente instalado, foi realizado a pré-molhagem, despejando-se 3,6 L de água no cilindro e cronometrando-se o tempo necessário para que toda a água infiltrasse. Para tempos de prémolhagem inferiores a $30 \mathrm{~s}$, utilizou-se $18 \mathrm{~L}$ de água para a realização do ensaio e cronometrou-se o tempo novamente (Figura 6c). Já para tempos superiores a $30 \mathrm{~s}$, a quantidade de água necessária passaria para 3,6 L, todavia tal fato não ocorreu em nenhum dos pontos testados. Vale mencionar que tanto na pré-molhagem como durante o ensaio, buscou-se manter um fluxo constante ao adicionar a água, tentando manter uma altura de lâmina da água entre 10 e $15 \mathrm{~mm}$ dentro do cilindro para garantir a correta execução do procedimento. Além disso, os experimentos foram realizados com um intervalo mínimo de 24 horas após a última precipitação registrada. Com os tempos devidamente registrados, obteve-se a taxa de infiltração $(\mathrm{k})$ in situ por meio da seguinte equação:

$$
\mathrm{k}=\frac{\mathrm{C} \cdot \mathrm{m}}{\left(\mathrm{d}^{2} \cdot \mathrm{t}\right)}
$$

em que k: taxa de infiltração expressa em milímetros por hora [mm/h];

$\mathrm{m}$ : massa de água infiltrada expressa em quilogramas [kg];

d: diâmetro interno do cilindro para toda a água percolar expresso em milímetros [mm];

t: tempo necessário para toda a água percolar expresso em segundos [s]; e

C: fator de conversão de unidades do sistema SI, com valor igual a 4583666000.

\section{RESULTADOS E DISCUSSÃO}

Os resultados obtidos para cada ponto ensaiado em termos de massa de água usada (kg), tempo de infiltração (s) e a taxa de infiltração (mm/h ou m/s) encontram-se apresentados na Tabela 2. 
Tabela 2: Resultados obtidos nos ensaios para determinação da taxa de infiltração in situ

\begin{tabular}{lllll}
\hline Ponto & Tempo de ensaio $(\mathbf{s})$ & Massa de água infiltrada $(\mathbf{k g})$ & Taxa de infiltração $(\mathbf{m m} / \mathbf{h})$ & Taxa de infiltração $(\mathbf{m} / \mathbf{s})$ \\
1 & 55,38 & 18 & 16553,51 & $4,60 \times 10^{-3}$ \\
2 & 52,08 & 18 & 17602,40 & $4,89 \times 10^{-3}$ \\
3 & 44,82 & 18 & 20453,66 & $5,68 \times 10^{-3}$ \\
4 & 53,83 & 18 & 17030,15 & $4,73 \times 10^{-3}$ \\
5 & 66,05 & 18 & 13879,38 & $3,86 \times 10^{-3}$ \\
6 & 41,38 & 18 & 22154,02 & $6,15 \times 10^{-3}$ \\
7 & 52,66 & 18 & 17408,53 & $4,84 \times 10^{-3}$ \\
8 & 57,46 & 18 & 15954,28 & $4,43 \times 10^{-3}$ \\
& & Média & 17629,49 & $4,89 \times 10^{-3}$ \\
\hline
\end{tabular}

Visando avaliar o grau de permeabilidade do pavimento, comparou-se os dados obtidos com os valores típicos de permeabilidade de solo (Tabela 3), conforme indica a NBR 16416 (ABNT, 2015). Contudo, ressalta-se que o método utilizado para obtenção de tais parâmetros é baseado em ensaio laboratorial unidirecional feito com auxílio de permeâmetros, diferentemente do ensaio em campo realizado nesta pesquisa.

Nota-se pelos valores encontrados que o pavimento apresentou uma taxa de infiltração de 4,89 x 10${ }^{3} \mathrm{~m} / \mathrm{s}$, valor considerado alto e bastante satisfatório, podendo ser comparado à permeabilidade de brita. Vale lembrar que o teste foi feito com o pavimento recém-construído (1 mês de uso com médio tráfego de circulação), estando livre de colmatação gerada ao longo do tempo, o que torna as condições de contorno favoráveis.

Já em uma análise pontual sobre os dois tipos de bases empregados, é possível perceber que não houve uma variação muito grande na taxa média de infiltração entre eles - vide Tabela 4. Todavia, o pavimento com base de agregado reciclado apresentou uma maior dispersão nos resultados, variando de $3,86 \times 10^{-3}$ a $6,15 \times 10^{-3} \mathrm{~m} / \mathrm{s}$, com um desvio padrão de $8,29 \times 10^{-4}$.

0 pavimento com base de agregado natural mostrou-se mais uniforme em termos de permeabilidade,

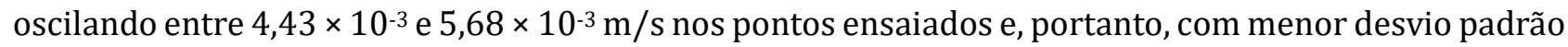
$\left(4,64 \times 10^{-4}\right)$. Uma das razões para isso pode estar na origem e procedência dos materiais, já que o agregado reciclado utilizado apresentou uma grande heterogeneidade em sua composição, com presença desde resíduos de cerâmica, ferro retorcido, borracha até vestígios de madeira, por exemplo.

Tabela 3: Valores típicos de permeabilidade de solos (ABNT, 2015)

\begin{tabular}{lll}
\hline Coeficiente de permeabilidade do solo $\mathbf{k}(\mathrm{m} / \mathbf{s})$ & Grau de permeabilidade do solo & Tipo de solo \\
$>10^{-3}$ & Alta & Brita \\
$10^{-3}$ a $10^{-5}$ & Média & Areia de brita, areia limpa, areia fina \\
$10^{-5}$ a $10^{-7}$ & Baixa & Areia, areia suja e silte arenoso \\
$10^{-7}$ a $10^{-9}$ & Muito baixa & silte, silte argiloso \\
$<10^{-9}$ & Praticamente impermeável & Argila \\
\hline
\end{tabular}

Para efeito de comparação com outros materiais usualmente adotados como revestimento permeável, encontrou-se na literatura estudos realizados sobre a permeabilidade de blocos de concreto intertravado com juntas alargadas do tipo trama e espinha de peixe (Marchioni e Silva 2013; Martins, 2014; Santos et al., 2015) e também da camada porosa de atrito (Pellizari, 2013). Em relação às peças de concreto com juntas alargadas, Marchioni e Silva (2013) apontam que se corretamente executado, os pavimentos intertravados permeáveis com junta de pelo menos $6 \mathrm{~mm}$ e rejuntados com pedrisco podem atingir coeficiente de permeabilidade na ordem de $10^{-4} \mathrm{~m} / \mathrm{s}$.

Cabe clarificar que nos estudos de Marchioni e Silva (2013) foram analisados dois tipos de pavimentos permeáveis de blocos intertravados utilizados como estacionamento com idades e tipos de paginação de assentamento diferentes. Enquanto o pavimento mais novo (recém-construído) com assentamento do tipo espinha de peixe (Figura 7a) obteve uma taxa de infiltração de 7,2 $\times 10^{-4} \mathrm{~m} / \mathrm{s}$, o pavimento com um ano de idade e padrão de assentamento do tipo trama (Figura $7 \mathrm{~b}$ ) apresentou uma permeabilidade 
um pouco inferior de aproximadamente $2,26 \times 10^{-4} \mathrm{~m} / \mathrm{s}$, evidenciando uma pequena perda da capacidade de infiltração ao longo tempo.

Por outro lado, estudos realizados por Martins (2014) em pavimentos intertravados convencionais com junta de $4 \mathrm{~mm}$ assentados e rejuntados com areia, indicaram resultados usualmente na ordem de $10^{-6} \mathrm{~m} / \mathrm{s}$, e portanto, de baixa permeabilidade. Diferentemente do pavimento permeável analisado por Marchioni e Silva (2013), os pavimentos estudados por Martins (2014) apresentavam revestimento de blocos intertravados tradicionais com aberturas de juntas menores $(4 \mathrm{~mm})$ rejuntados com material com baixa quantidade de vazios e distribuição granulométrica mais fechada, contribuindo para as baixas taxas de infiltração encontradas. Embora os trabalhos citados não apresentem as curvas granulométricas ou porosidade dos agregados empregados, eles fazem tal constatação sobre a composição da camada de revestimento.

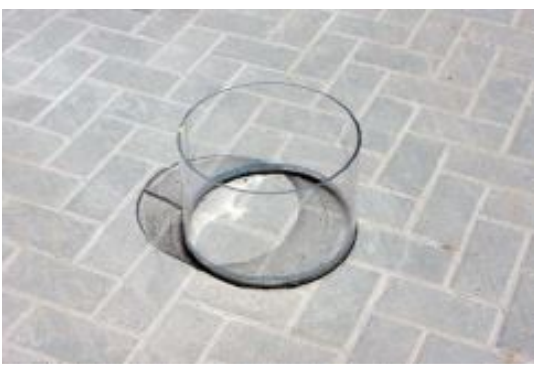

(a)

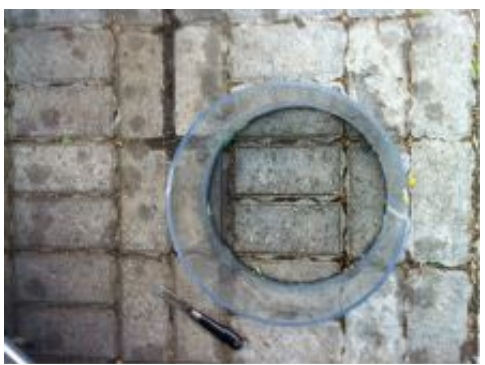

(b)

Figura 7. Ensaio de permeabilidade in situ em pavimentos permeáveis com revestimento de blocos de concreto intertravados (Marchioni e Silva, 2013): (a) pavimento novo com paginação do tipo espinha de peixe e (b) pavimento com um ano de idade com paginação do tipo trama

Martins (2014) pesquisou a permeabilidade de blocos intertravados tradicionais (usados como calçadas) tanto com diferentes idades (novos e antigos), como também com diferentes tipos de paginação de assentamento (espinha de peixe e trama). Dos resultados obtidos, foi possível observar que pavimentos mais novos apresentaram valores ligeiramente maiores de infiltração, com média de 7,98 × 10-6 m/s para novos contra 7,12 × 10-6 $\mathrm{m} / \mathrm{s}$ para antigos.

Já em relação ao tipo de assentamento, blocos com juntas alargadas do tipo espinha de peixe (Figura 8a) mostraram-se mais permeáveis do que blocos com junta alargada do tipo trama (Figura 8b). Enquanto o tipo espinha de peixe registrou $8,8 \times 10^{-6} \mathrm{~m} / \mathrm{s}$, o tipo trama registrou 7,16 $\times 10^{-6} \mathrm{~m} / \mathrm{s}$, estando ambos na mesma condição nova de conservação e idade. Martins (2014) explicou a diferença encontrada devido ao fato da paginação tipo trama possuir uma menor área de juntas, logo uma menor área de infiltração.

Corroborando com a ordem de grandeza encontrada por Martins (2014), Santos et al. (2015) realizaram o mesmo método de ensaio num pavimento permeável de bloco de concreto intertravado com juntas alargadas do tipo espinha de peixe usado há 7 anos como calçada sem manutenção em um Parque Ecológico de Goiânia. Os resultados indicaram uma taxa de infiltração de 1,99 × 10-6 m/s, valor considerado baixo.

Comparando-se com o revestimento asfáltico poroso, a permeabilidade dos blocos articulados também se apresentou superior, com uma taxa de infiltração aproximadamente cem vezes maior. Pellizari (2013) em sua análise experimental para avaliar a eficácia na restauração da capacidade de infiltração da camada superior de pavimentos porosos, mediu o coeficiente de permeabilidade do pavimento de um estacionamento teste (médio tráfego de circulação) feito com CPA (camada porosa de atrito) tanto na condição colmatada como também após intervenções corretivas de manutenção (Figura 8c).

É válido ponderar que o estacionamento estudado por Pellizari (2013) possui seção com $7 \mathrm{~cm}$ de espessura para a camada de revestimento drenante e de 26 a $34 \mathrm{~cm}$ de altura para a camada de base 
granular, comportando-se como um pavimento permeável. Aos oito anos de idade, o pavimento apresentava permeabilidade média de $1,69 \times 10^{-5} \mathrm{~m} / \mathrm{s}$, quando ainda não havia passado por processo de manutenção. Após as medidas de recuperação com jato de ar e água, a taxa de infiltração subiu para 5,25 × 10${ }^{5} \mathrm{~m} / \mathrm{s}$, valor considerado de média permeabilidade, mas ainda inferior aos encontrados com o bloco de concreto unidirecionalmente articulado.

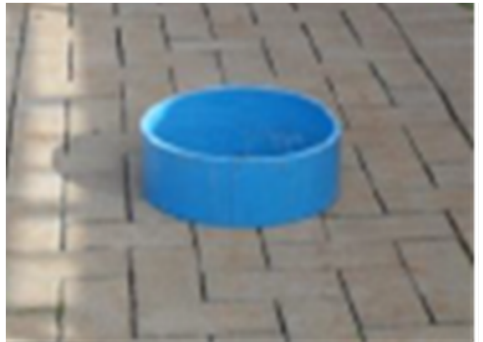

(a)

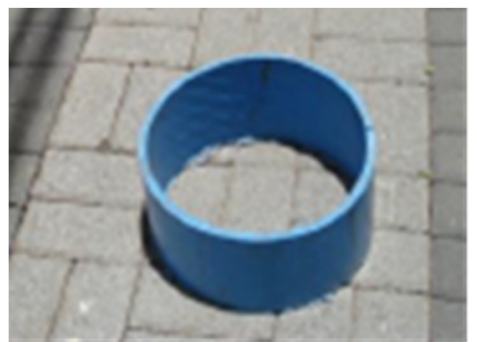

(b)

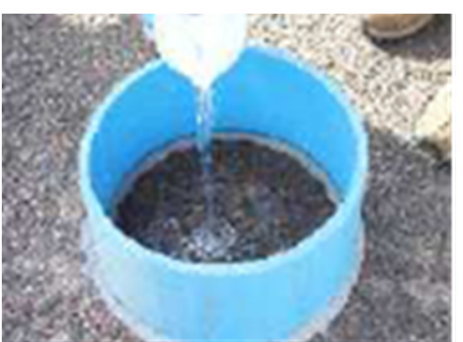

(c)

Figura 8. Ensaio de permeabilidade in situ com diferentes materiais de revestimento permeável: (a) bloco de concreto com junta alargada do tipo espinha de peixe (Martins, 2014); (b) bloco de concreto com junta alargada do tipo trama (Martins, 2014); (c) camada porosa de atrito (Pellizari, 2013)

O quadro-resumo com todos os dados levantados pelos autores supracitados podem ser vistos na Tabela 5.

Tabela 5: Levantamento da taxa de infiltração in situ em diferentes tipos de revestimentos permeáveis

\begin{tabular}{lllll}
\hline Referência & Tipo de Revestimento & Aplicação & Condição do Pavimento & $\begin{array}{l}\text { Taxa de Infiltração } \\
\text { (m/s) }\end{array}$ \\
\hline Marchioni e Silva (2013) & Bloco c/ juntas alargadas (espinha) & Estacionamento & Novo & $7,2 \times 10^{-4}$ \\
Marchioni e Silva (2013) & Bloco c/ juntas alargadas (trama) & Estacionamento & Antigo (sem manutenção) & $2,26 \times 10^{-4}$ \\
Martins (2014) & Bloco c/ juntas alargadas (espinha) & Calçada & Novo & $8,80 \times 10^{-6}$ \\
Martins (2014) & Bloco c/ juntas alargadas (trama) & Calçada & Novo & $7,16 \times 10^{-6}$ \\
Martins (2014) & Bloco c/ juntas alargadas (espinha) & Calçada & Antigo (sem manutenção) & $7,45 \times 10^{-6}$ \\
Martins (2014) & Bloco c/ juntas alargadas (trama) & Calçada & Antigo (sem manutenção) & $6,79 \times 10^{-6}$ \\
Pellizari (2013) & Camada porosa de atrito (CPA) & Estacionamento & Antigo (sem manutenção) & $1,69 \times 10^{-5}$ \\
Pellizari (2013) & Camada porosa de atrito (CPA) & Estacionamento & Antigo (sem manutenção) & $5,25 \times 10^{-5}$ \\
Santos et al. (2015) & Bloco c/ juntas alargadas (espinha) & Calçada & Antigo (sem manutenção) & $1,99 \times 10^{-6}$ \\
\hline
\end{tabular}

\section{CONSIDERAÇÕES FINAIS}

A partir da construção do pavimento teste, bem como da execução dos ensaios de permeabilidade in situ e discussão dos resultados, foi possível pontuar as seguintes constatações:

- O revestimento constituído de blocos de concreto unidirecionalmente articulado conferiu ao pavimento uma permeabilidade elevada de 4,89 × $10^{-3} \mathrm{~m} / \mathrm{s}$, comparável à permeabilidade de brita. Tal fato pode ser explicado pela própria estrutura geométrica da peça que facilita a drenagem por meio de cavidades auxiliares, somada às articulações que garantem o travamento e dispensam o uso de material de rejunte.

- A taxa de infiltração da estrutura de pavimento articulado estudada em campo apresentou valores superiores àqueles obtidos em outras pesquisas com materiais permeáveis comumente usados como o bloco intertravado com junta alargada e o asfalto poroso cujos resultados giraram na maioria dos casos na ordem de $10^{-6}$ e $10^{-5} \mathrm{~m} / \mathrm{s}$, respectivamente. Todavia, vale recordar que embora os autores tenham utilizado o mesmo método experimental, as comparações feitas consideram pavimentos em diferentes condições de uso, espaçamento de juntas, estado de conservação, idade, volume de tráfego e aplicação (calçada ou estacionamento), já que os estudos foram feitos em locais diferentes. Por- 
tanto, os parâmetros observados servem apenas de estimativas para comparações preliminares.

- A permeabilidade do pavimento não apresentou variação significativa devido ao tipo de base empregado. Enquanto o trecho executado com agregado reciclado obteve coeficiente médio de permeabilidade de $4,87 \times 10^{-3} \mathrm{~m} / \mathrm{s}$, o trecho com agregado natural apresentou uma média de 4,94 × 10-3 m/s. Contudo, dentro dos valores pontuais da área com base de RCD, houve uma maior oscilação dos resultados (maior desvio padrão), explicada pela própria heterogeneidade típica da composição do material reciclado.

A pesquisa ainda suscita questionamentos acerca da realização de ensaio para determinação da resistência característica à compressão especificada pela NBR 9781 (única norma aplicada a peças de concreto para pavimentação), cujos procedimentos não preveem o uso de peças articuladas e nem abrangem diferentes formatos e estruturas geométricas, dando margem, portanto, a possíveis revisões. Uma vez que nesse tipo de bloco a área superficial é diferente da área inferior que transmite o carregamento para a estrutura subjacente, poderia considerar-se a área útil como sendo a resultante da relação do volume pela altura do bloco, conforme já indicam as normas americanas ASTM C140 (2016) e ASTM D6684 (2014) para blocos de concreto articulados.

\section{AGRADECIMENTOS}

Os autores agradecem à Coordenação de Aperfeiçoamento de Pessoal de Nível Superior (CAPES) pela bolsa de pesquisa, ao Laboratório de Tecnologia de Pavimentação (LTP) e Construção Civil (PCC) da EPUSP pelo auxílio e suporte prestados, à Ecounion (fornecedora dos blocos articulados) e à prefeitura do campus USP da capital pela parceria e apoio no projeto de pesquisa.

\section{REFERÊNCIAS}

ABNT (2013) NBR 9781 - Peças de concreto para pavimentação - Especificação e métodos de ensaio. Associação Brasileira de Normas Técnicas, Rio de Janeiro.

ABNT (2015) NBR 16416 - Pavimentos permeáveis - requisitos e procedimentos. Associação Brasileira de Normas Técnicas, Rio de Janeiro.

Araújo, P. R; Tucci, C.E.; Goldenfum, J. A. (2000) Avaliação da eficiência dos pavimentos permeáveis na redução do escoamento superficial. RBRH - Revista Brasileira de Recursos Hídricos. v. 5, n. 3, p. 21-29. DOI: 10.21168/rbrh.v5n3.p21-29.

ASTM (2009) C1701/C1701M - Standard test method for infiltration rate of in place pervious concrete. American Society for Testing and Materials, West Conshohocken, Pensilvânia.

ASTM (2014) D6684 - Standard specification for materials and manufacture of articulating concrete block revetment systems. American Society for Testing and Materials, West Conshohocken, Pensilvânia.

ASTM (2016) C140 - Standard tests methods for sampling and testing concrete masonry and related units. American Society for Testing and Materials. West Conshohocken, Pensilvânia.

ASCE (1992) - Design and construction of urban stormwater management systems. American Society Of Civil Engineers. New York.

Marchioni, M. S.; Silva C. O. (2013) Método de ensaio para avaliação de pavimento permeável executado. In: Anais do 55ํㅡㄴ Congresso Brasileiro do Concreto, Gramado.

Martins, R. M. (2014) Análise da Capacidade de Infiltração do Pavimento Intertravado de Concreto. Universidade Tecnológica Federal do Paraná, Pato Branco.

Pellizzari, V. (2013) Avaliação da Eficácia da Restauração da Capacidade de Infiltração da Camada Superior de Pavimentos Porosos. Trabalho de Conclusão de Curso. Universidade Federal do Rio Grande do Sul - Departamento de Engenharia Civil, Porto Alegre.

Pinto, L. L (2011) O desempenho de pavimentos permeáveis como medida mitigadora da impermeabilização do solo urbano. Tese de doutorado - Escola Politécnica da Universidade de São Paulo. São Paulo, 2011.

Sales, T. D. (2008). Pavimento permeável com superfície em blocos de concreto de alta porosidade. Dissertação de Mestrado. Universidade Federal de Santa Catarina, Florianópolis.

Santos, L. P.; Cuba, R. M.; Leitão, V. S.; Neto, A. S. (2015) Análise da eficiência de calçadas ecológicas como sistema de drenagem sustentável nos centros urbanos: estudo de caso no Parque Flamboyant, Goiânia-Goiás. Revista Eletrônica em Gestão, Educação e Tecnologia Ambiental, v. 19, n. 3, p. 837-849. DOI: 105902/2236117018345.

Seoul Metropolitan Government - SMG (2014) Importance of the technology: field permeability test. Apresentação em PowerPoint. Seoul.

Tucci, C. M.; Tozzi, M. J. (1998) Drenagem urbana: gerenciamento, simulação, controle. Associação Brasileira de Recursos Hídricos, p. 155-163. Editora UFRGS, Porto Alegre.

Tucci, C. M.; Bertoni, J. C. (2003) Inundações urbanas na América do Sul. Associação Brasileira de Recursos Hídricos, Porto Alegre. 
Virgiliis, A. D. (2009). Procedimentos de projeto e execução de pavimentos permeáveis visando retenção e amortecimento de picos de cheias. Dissertação de Mestrado - Escola Politécnica da Universidade de São Paulo, São Paulo.

Weiss, P. T.; Kayhanian, M.; Khazanovich, L.; Gulliver, J. S. (2015) Permeable pavements in cold climates: state of the art and cold climate case studies - Report. Center for Transportation Studies. University of Minessota, Minneapolis. 